University of Nebraska - Lincoln

DigitalCommons@University of Nebraska - Lincoln

Civil and Environmental Engineering Faculty

Publications

Civil and Environmental Engineering

2017

\title{
Calibrating the Robertson's Platoon Dispersion Model on a Coordinated Corridor with Advance Warning Flashers
}

Zhao Li

University of Nebraska-Lincoln, li@huskers.unl.edu

Laurence Rilett

University of Nebraska-Lincoln, Irilett2@unl.edu

Ernest Tufuor

University of Nebraska - Lincoln, ernest.tufuor@huskers.unl.edu

Follow this and additional works at: https://digitalcommons.unl.edu/civilengfacpub

Part of the Navigation, Guidance, Control, and Dynamics Commons, and the Transportation

Engineering Commons

$\mathrm{Li}$, Zhao; Rilett, Laurence; and Tufuor, Ernest, "Calibrating the Robertson's Platoon Dispersion Model on a Coordinated Corridor with Advance Warning Flashers" (2017). Civil and Environmental Engineering Faculty Publications. 174.

https://digitalcommons.unl.edu/civilengfacpub/174

This Article is brought to you for free and open access by the Civil and Environmental Engineering at DigitalCommons@University of Nebraska - Lincoln. It has been accepted for inclusion in Civil and Environmental Engineering Faculty Publications by an authorized administrator of DigitalCommons@University of Nebraska Lincoln. 


\title{
Calibrating the Robertson's Platoon Dispersion Model on a Coordinated Corridor with Advance Warning Flashers
}

\author{
Li Zhao, Laurence R. Rilett, and Ernest Tufuor \\ Nebraska Transportation Center, University of Nebraska-Lincoln \\ Prem S. Paul Research Center at Whittier School, 2200 Vine Street, Lincoln, NE 68583 \\ Corresponding author — L. Zhao, li@huskers.unl.edu
}

\begin{abstract}
Platoon dispersion (PD) is the foundation of traffic signal coordination in an urban traffic network. PD describes the phenomenon by which vehicles depart from an upstream intersection as a platoon and begin to disperse before they arrive at the downstream intersection. Recently, advance warning flashers (AWFs) have been applied in many high-speed corridors. There is a need to update the traditional PD model to include the effect of AWFs. This paper examines the traffic flow dispersion patterns when an AWF is present and tests the hypothesis that the AWF will affect PD on a coordinated signal corridor. Platoon vehicles, which are not affected by the operation of the AWF, are used for comparison. Results show that when the AWF effect is included in the PD model, the smoothing factor $F$ of the Robertson's PD model ranges from 0.11 to 0.13 . This range is smaller than the smoothing factor without the AWF effect. The platoon

Published in Transportation Research Record: Journal of the Transportation Research Board, No. 2623 (2017), pp 10-18.

doi 10.3141/2623-02

Copyright (C) 2017 by National Academy of Sciences; published by SAGE Publications. Used by permission.

The Standing Committee on Traffic Flow Theory and Characteristics peer-reviewed this paper. The contents of this paper reflect the views of the authors, who are responsible for the facts and the accuracy of the information presented, and are not necessarily representative of the sponsoring agency.
\end{abstract}


arrival time coefficient a ranges from 0.777 to 0.819 with the AWF effect. This is approximately the same as the default value of 0.8 in the TRANSYT simulation model. The PD coefficient $\beta$ increases from an average of 0.11 with the AWF effect to an average of 0.24 without the AWF effect, which indicates an increase in roadway friction. It was concluded that AWFs increase the dispersion of the platoons, which might affect signal coordination.

Traffic signal coordination in a corridor involves choosing signal timing parameters (e.g., cycle length, green time, number of phases) to optimize various objectives, such as reducing fuel consumption, reducing emissions, maximizing throughput, and reducing delay. For optimizing traffic signals on a corridor, the start of green at a downstream intersection is often set so that the waiting vehicles discharge before platoon arrival from the upstream intersection. A key requirement for an optimal signal coordination strategy is understanding how the platoon of vehicles that are released from the upstream intersection arrives at the downstream intersection.

When the green phase at the upstream intersection starts, it releases a platoon of vehicles that travel to the downstream signalized intersection. As this platoon moves downstream, the vehicles that compose the platoon disperse. In other words, the headway between vehicles increases because of the differences in vehicle speeds, vehicle interactions (lane changing, merging, etc.), and roadway friction (e.g., on-road parking, pedestrians). This phenomenon is called platoon dispersion (PD). When a platoon of vehicles is released from an upstream traffic signal, the degree to which this platoon has dispersed at the downstream signalized intersection in part determines whether significant benefits can be achieved from signal coordination. In general, the effectiveness of signal timing and progression diminishes as PD increases.

Recently, advance warning flasher (AWF) systems have been implemented to alert drivers that the green phase at the downstream intersection will be ending soon. This information can reduce indecision and variability in driver behavior at the onset of amber (1). Figure 1 shows a typical AWF system design with two flashing signal heads mounted on top of warning signs with the legend "Prepare To Stop When Flashing." The AWF sign is positioned on either side of the approach direction and placed at a safe distance from the downstream intersection. In addition, the AWF is connected to the intersection signal controller so that 


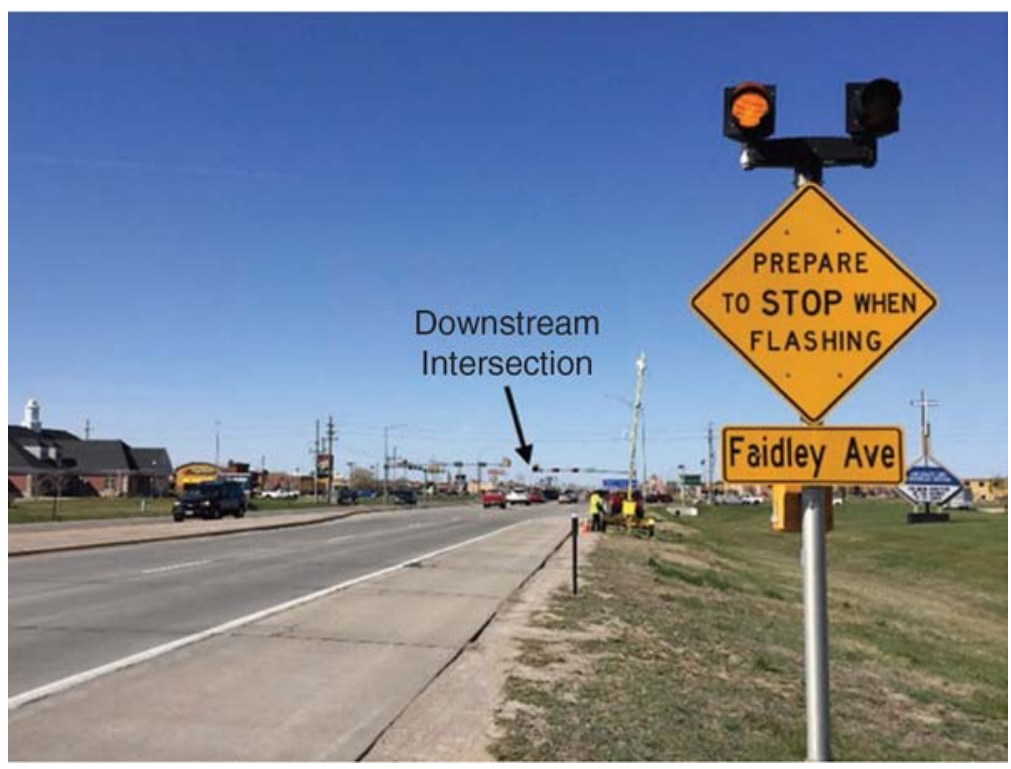

Figure 1. AWF and sign assembly, US-281, Grand Island, Nebraska.

when the downstream signal is about to transition from green to amber, the flasher is turned on to warn approaching drivers of the impending phase change. According to Nebraska Department of Roads standards, the AWF signal heads are designed to begin flashing 5 to $7 \mathrm{~s}$ before the onset of the amber indication at the downstream signalized intersection.

Previous research on high-speed, isolated intersections found that drivers tend to slow when the AWF is activated (2). When the AWF is placed in a coordinated signalization system corridor, it is not clear whether the AWF affects PD. It is necessary to understand how an AWF affects PD so that such effects can be accounted for in the signal coordination methodology.

\section{Robertson's PD Model}

In 1968, Robertson proposed a PD model that was embedded in the traffic network study tool (TRANSYT) simulation model (3). This model is one of the most widely used signal optimization models around the world. The core of the TRANSYT traffic flow model is Robertson's PD model (4), which describes the dispersion of a vehicle platoon departing from an upstream signalized intersection, as illustrated in Figure 2. 


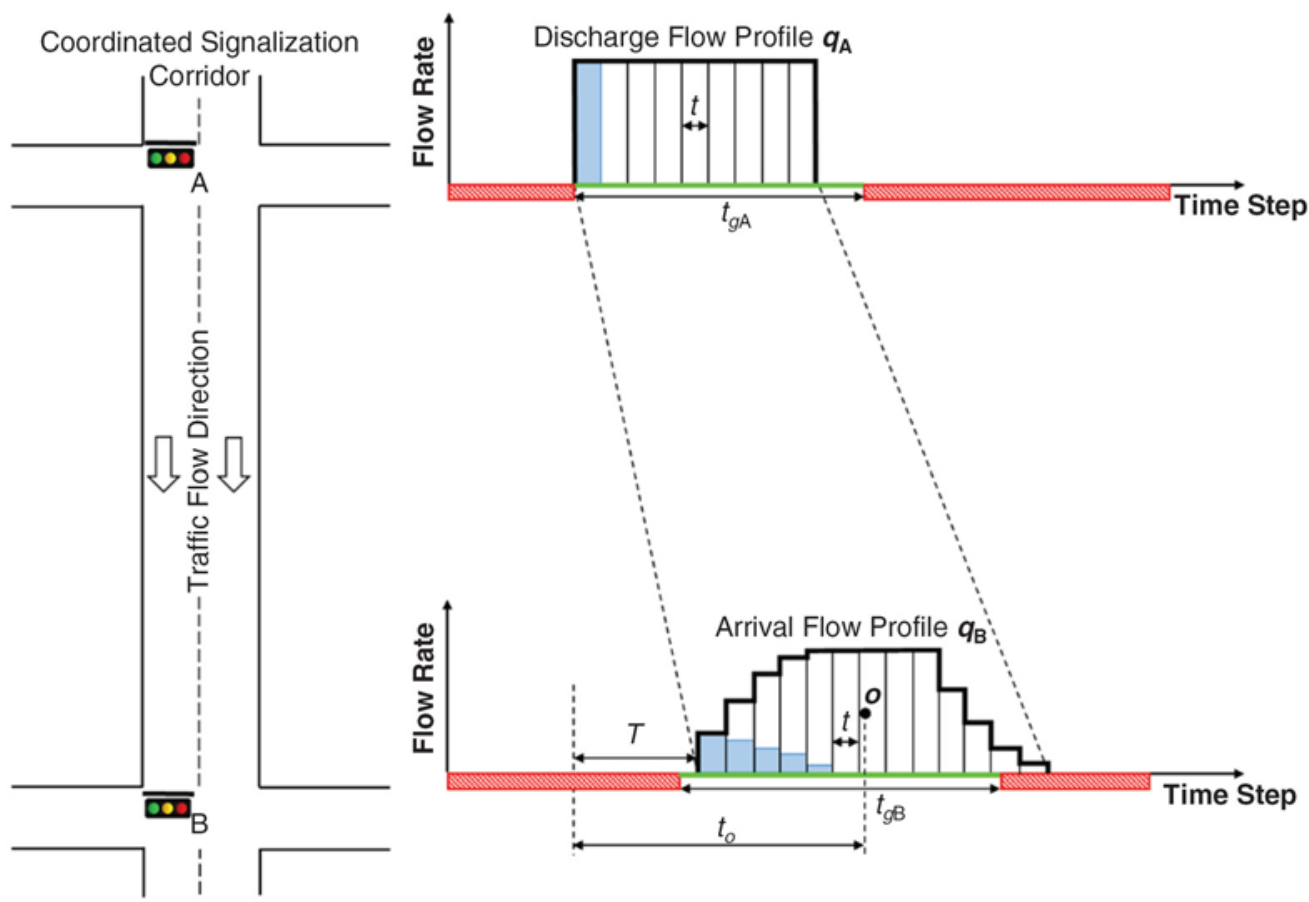

Figure 2. Robertson's PD model.

Figure 2 shows flow rate as a function of time step $t$ at two intersections, A and B. For a coordinated corridor, the two signalized intersections $\mathrm{A}$ and $\mathrm{B}$ should have a common cycle length. The green times, $t_{\mathrm{gA}}$ and $t_{\mathrm{gB}}$, are not necessarily equal. Robertson's model assumes an upstream departure flow $q_{\mathrm{A}}$, which discharges at the saturation flow starting at the beginning of the effective green. The first vehicle shifts a lag time of $T$ when arriving at Intersection B. The average travel time of the vehicles in the platoon is denoted by $t_{0}$. It is assumed that for each time step, the arrival flow $q_{\mathrm{B}}$ follows a geometric distribution, as illustrated in the first time step in Figure 2 (shaded area). The figure shows that the platoon disperses as it travels down the road. The process is described mathematically with Robertson's PD model, as shown in Equation 1, which indicates that any arrival flow to the downstream location, B, is a weighted combination of $(a)$ the discharge flow at the upstream location, A, where the traffic flow departed a lag time $T$ ago, and $(b)$ the arrival flow at the downstream location, $\mathrm{B}$, in the previous second $(t-1)$.

$$
q_{\mathrm{B}(t)}=F q_{\mathrm{A}(t-T)}+(1-F) q_{\mathrm{B}(t-1)}
$$


where

$q_{\mathrm{A}(t)}=$ discharge flow at upstream location A of the link as a function of time step $t$ (in units of vehicles per time step);

$q_{\mathrm{B}(t)}=$ arrival flow at downstream location $\mathrm{B}$ of the link as a function of time step $t$ (in units of vehicles per time step);

$T=$ lag time for arrival of the first vehicle in the platoon, also known as platoon arrival time (in units of time step); and

$F=$ smoothing factor (unitless).

The smoothing factor $(F)$ is a function of the platoon travel time to the downstream signal and roadway impedance to traffic flow, or friction. The platoon travel time $\left(t_{o}\right)$ is the average of the running time of all vehicles in a platoon from the upstream location to the downstream location. From empirical evidence, Robertson found that the platoon arrival time $(T)$ is a portion of the average of the platoon travel time $\left(t_{0}\right)$ and $F$ is a function of two parameters: the PD factor $\alpha(0 \leq \alpha \leq 1)$ and the travel time factor $\beta(0 \leq \beta \leq 1)$ (3). These are estimated with Equations 2 and 3 .

$$
\begin{aligned}
& T=\beta t_{o} \\
& F=\frac{1}{1+\alpha \beta t_{o}}
\end{aligned}
$$

The average platoon travel time ( $t_{o}$, in units of time step) can be estimated by field observation of vehicles traveling as a platoon after the start of the green at the upstream intersection. It has been found that different link travel times result in the selection of different $\alpha$ and $\beta \beta$ values, even when road conditions are similar (5). A successful application of Robertson's PD model relies on the appropriate calibration of several model parameters. In TRANSYT-7F, the default values of $\alpha$ and $\beta$ are 0.35 and 0.80 , respectively (6). In general, as roadway friction increases (e.g., parking on road, high volume of pedestrians, narrow lane widths), $\alpha$ increases. Other values of $\alpha$ and $\beta$ reported in the literature are listed in Table 1.

Besides the recommended values of $\alpha$ and $\beta$ in Table 1 , some researchers argue that the $\alpha$ and $\beta$ values should be calibrated for each specific site to capture the site-specific geometric and traffic conditions 
Table 1. Recommended Values for PD Parameters

\begin{tabular}{|c|c|c|c|c|}
\hline Site Description & $\alpha$ & $\beta$ & Reference & Note \\
\hline Urban $C B D$, heavy friction & 0.50 & 0.80 & $\begin{array}{l}\text { Tarnoff and Parsonson } 1981 \text { ( } 7 \text { ) } \\
\text { and pedestrian traffic }\end{array}$ & Narrow lanes with parking, heavy turns, \\
\hline CBD arterial, moderate friction & 0.35 & 0.80 & vehicles and pedestrian traffic & Well-designed with light turning \\
\hline Suburban arterial, low friction & 0.25 & 0.80 & & $\begin{array}{l}\text { Turning provisions } 12-\mathrm{ft} \text { lane width, } \\
\text { no parking }\end{array}$ \\
\hline Two-lane, low friction & 0.21 & 0.97 & $\begin{array}{l}\text { McCoy et al. } 1983 \text { (8) } \\
\text { four observers }\end{array}$ & Two sites with speed limits of $35 \mathrm{mph}$, \\
\hline Four-lane, low friction & 0.15 & 0.97 & four observers & Four sites with speed limits of $45 \mathrm{mph}$, \\
\hline Three-lane, medium friction & 0.40 & 0.80 & $\begin{array}{l}\text { Seddon } 1972(9) \\
10 \%-15 \% \text { commercial vehicles }\end{array}$ & Reasonable freedom to overtake with \\
\hline Ten urban intersections & $0.13-0.36$ & $0.84-0.95$ & Bonneson et al. $2010(10)$ & Speed limits varying from 35 to $50 \mathrm{mph}$ \\
\hline Three-lane highway & 0.20 & 0.80 & Collins and Gower 1974 (11) & Suburban arterial \\
\hline Single-lane, downstream 420 m & 0.60 & 0.63 & $\begin{array}{l}\text { El-Reedy and Ashworth } \\
1978 \text { (12) }\end{array}$ & $\begin{array}{l}\text { 10-m-wide lane, } 5 \% \text { downgrade, speed } \\
\text { limit } 30 \mathrm{mph}, 12 \text { buses } / \mathrm{h}\end{array}$ \\
\hline Single-lane, downstream 560 m & 0.70 & 0.59 & & \\
\hline $\begin{array}{l}\text { Eight sites in wide range of } \\
\text { friction from light to heavy }\end{array}$ & $0.23-0.53$ & 0.80 & Axhausen and Körling 1987 (13) & $\begin{array}{l}\text { Consideration of number of lanes, slope, } \\
\text { parking, pedestrians, and flow rate }\end{array}$ \\
\hline $\begin{array}{l}\text { Nine coordinated intersections } \\
\text { with a few driveways }\end{array}$ & $a$ & $a$ & Day and Bullock 2012 (14) & $\begin{array}{l}\text { Posted speed limit } 55 \mathrm{mph} \text {; corridor } \\
\text { had mixed land use }\end{array}$ \\
\hline
\end{tabular}

$\mathrm{CBD}=$ central business district.

a. $\alpha \beta=0.17$ was determined to be the best fit.

$(15,16)$. Given an assumption that the platoon travel time follows a shifted geometric distribution, Yu and Van Aerde (17) and Yu (18) proposed a simplified method to calibrate the PD parameters, as shown in Equations 4 and 5.

$$
\begin{aligned}
& \alpha=\frac{\sqrt{1+4 \sigma_{t_{o}}^{2}}-1}{2 t_{o}+1-\sqrt{1+4 \sigma_{t_{o}}^{2}}} \\
& \beta=\frac{2 t_{o}+1-\sqrt{1+4 \sigma_{t_{o}}^{2}}}{2 t_{o}}
\end{aligned}
$$

In essence, the dispersion factors $\alpha$ and $\beta$ are related to the average platoon travel time $\left(t_{o}\right)$ and the variance of the travel time $\left(\sigma_{t o}^{2}\right)$. As $\sigma_{t o}^{2}$ increases, the dispersion factor $\alpha$ becomes larger and $\beta$ becomes smaller, which indicates a more spread-out platoon.

When an AWF is located between the upstream and downstream intersections, a natural question is whether the flashing signal affects PD. 
However, a comprehensive literature review found that none of the existing research has considered the effect of AWF on PD or signal coordination. It is hypothesized in this paper that PD will be affected by the presence of an AWF. If true, suboptimal signal coordination may result if this effect is ignored. This paper analyzes whether this hypothesis is true.

\section{Sites and Data Collection}

The test sites are located on US-281 in Grand Island, Nebraska, as shown in Figure 3. The traffic signals on the north-south corridor of US-281 are coordinated with a common cycle length of $79 \mathrm{~s}$. The speed limit on the four-lane, two-way corridor is $45 \mathrm{mph}$. The coordinated corridor

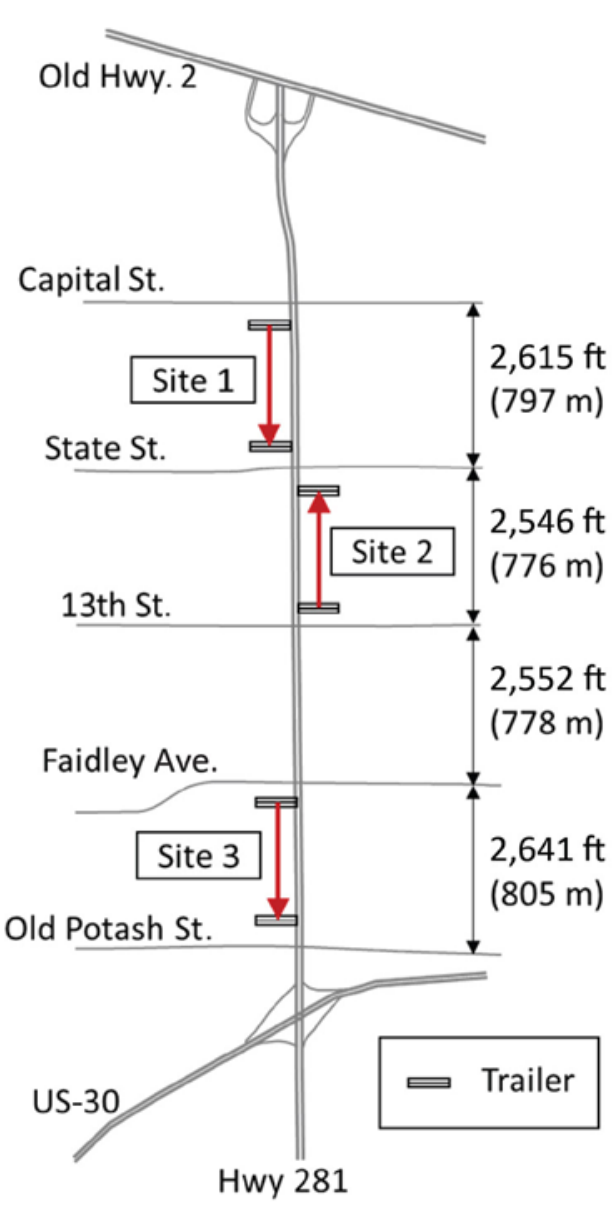

(a)

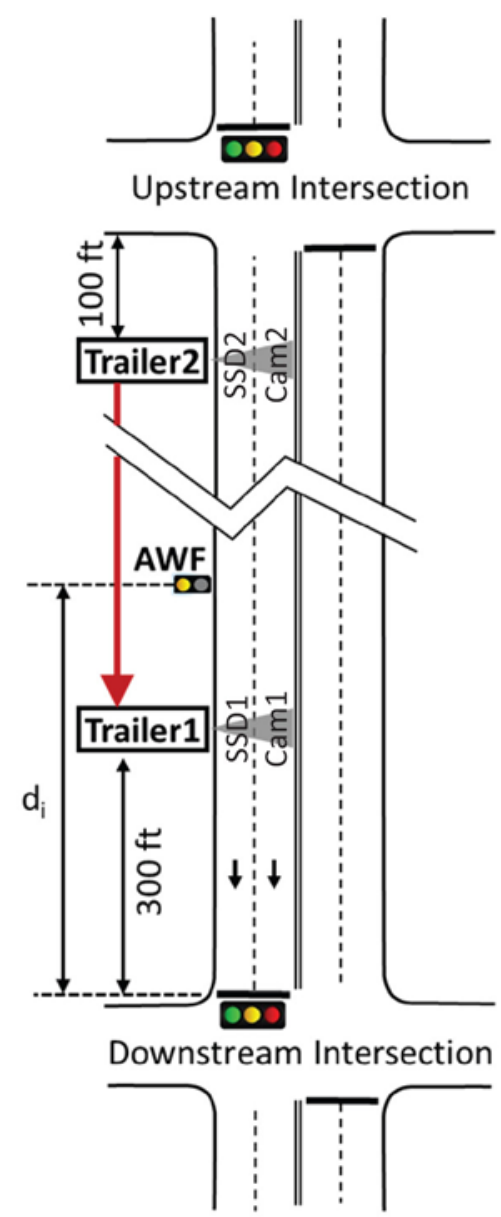

(b)

Figure 3. (a) Test sites at US-281 and $(b)$ generic data collection system layout. 
has semiactuated control, where the signal phases for the cross streets (e.g., the minor roads) are actuated according to the volume on the cross streets. In addition, standard access management techniques were used in the design of this corridor, thus there are no access or egress points on US-281 between any two signalized intersections.

Three test sites were used in this study, as shown in Figure $3 a$. They are Site 1, a southbound link from Capital Street to State Street; Site 2, a northbound link from 13th Street to State Street; and Site 3, a southbound link from Faidley Avenue to Old Potash Street. The AWFs are located upstream of the traffic signal. As illustrated in Figure $3 b, d_{i}$ represents the distance from the AWF to the stop line at site $i$, where $d_{1}=$ $550 \mathrm{ft}, d_{2}=520 \mathrm{ft}$, and $d_{3}=525 \mathrm{ft}$. The rate of heavy vehicles on US-281 ranges from $6 \%$ to $11 \%$.

For each site, two mobile trailers were used to collect data. A generic representation of the data collection setup is shown in Figure $3 b$. Trailer 1 was located $300 \mathrm{ft}$ upstream from the stop line of the downstream intersection. This location was chosen because the AWF effect on vehicle speed could be captured, but it was unlikely the driver's speed would be affected by queueing at the downstream intersection because it was a considerable distance down the road. Trailer 2 was located $100 \mathrm{ft}$ away from the nearest edge of the upstream intersection. This location was chosen because the immediate traffic outflow from the upstream intersection could be readily identified. On each mobile trailer, a Wavetronix SmartSensor HD (SSD) sensor and a camera were installed perpendicular to the traffic. The SSD was used to automatically record the time at which each vehicle passed the trailer location. The camera was used to videotape the traffic passing the trailer in case the SSD data had to be checked visually. The video range of the upstream camera (i.e., the camera on Trailer 2) covered the upstream intersection signal so that the time of signal change could also be recorded. In addition, a Mikrotik SXT $5 \mathrm{HnD}$ router was used to wirelessly connect the two trailers so that all the data were synchronized and saved in the local server, which was in the Trailer 1 cabinet. A 1-s time step was used for both the SSD and the video data collection.

The signal timing from the upstream intersection was collected directly from traffic signal control cabinets. Specifically, a Raspberry PIbased single-board computer was modified to capture the electronic pulse from magnetic sensors attached to the cabinet circuity. The computer recorded the on and off times for each phase. 
Table 2. Summary of Test Site Characteristics

\begin{tabular}{|c|c|c|c|c|c|c|c|c|}
\hline \multirow[t]{2}{*}{ Site } & \multirow[t]{2}{*}{$\begin{array}{l}\text { Upstream } \\
\text { (from) }\end{array}$} & \multirow[t]{2}{*}{$\begin{array}{l}\text { Downstream } \\
\text { (to) }\end{array}$} & \multirow{2}{*}{$\begin{array}{l}\text { Peak Hour } \\
\text { Volume } \\
\text { (vphpl) }\end{array}$} & \multirow[t]{2}{*}{$\begin{array}{l}\text { Signal } \\
\text { Cycles }\end{array}$} & \multicolumn{2}{|c|}{$\begin{array}{l}\text { Speed at } \\
\text { Trailer } 1 \text { (mph) }\end{array}$} & \multicolumn{2}{|c|}{$\begin{array}{l}\text { Speed at } \\
\text { Trailer } 2 \text { (mph) }\end{array}$} \\
\hline & & & & & Mean & $85 \%$ & Mean & $85 \%$ \\
\hline 1 & Capital St. & State St. & 283 & 638 & 30.8 & 41.4 & 36.3 & 45.1 \\
\hline 2 & 13th St. & State St. & 385 & 637 & 33.7 & 42.2 & 36.6 & 45.9 \\
\hline 3 & Faidley Ave. & Old Potash St. & 596 & 637 & 32.9 & 42.2 & 36.6 & 45.8 \\
\hline
\end{tabular}

vphpl = vehicles per hour per lane

Data were collected on May 17 and 18, May 27 and 28, and June 4 and 5, 2016, at Sites 1, 2, and 3, respectively. No rain or other harsh weather occurred on these days. The data collection for each site began at 4 p.m. on the first day and ended at 6 p.m. on the second day for a total collection period of $26 \mathrm{~h}$ per site. The data from the first day at $8 \mathrm{p} . \mathrm{m}$. to the second day at 6 a.m. were removed because of low traffic volume and corresponding small platoon sizes. A statistical summary of the data from the three sites is given in Table 2 .

The identification of the platoon for each cycle was automated into the R programming language through the following three steps:

1. Identify the "on" of the green phase $\left(t_{\text {on }}\right)$ and the "off " of the green phase $\left(t_{\text {off }}\right)$ from the upstream signal intersection. Match the start and end of the green phase to the SSD data at the upstream trailer (Trailer 2 ) and the downstream trailer (Trailer 1).

2. Use the count data from the upstream trailer to identify the discharge platoon as a function of time for each cycle. The discharge platoon in each cycle starts when the green phase is on and ends when the green phase is off, as shown in Equations 6 and 7.

$$
\begin{aligned}
& t_{d, i, n, \text { start }}=t_{\mathrm{on}, i, n} \\
& t_{d, i, n, \text { end }}=t_{\text {off }, i, n}
\end{aligned}
$$

where

$t_{d, i, n, \text { start }}=$ start time of the discharge platoon for cycle $n$ at site $i$,

$t_{d, i, n, \text { end }}=$ end time of the discharge platoon for cycle $n$ at site $i$,

$t_{\mathrm{on}, i, n}=$ upstream green phase on for cycle $n$ at site $i$, and

$t_{\mathrm{off}, i, n}=$ upstream green phase off for cycle $n$ at site $i$. 
3. Use the count data from the downstream trailer to identify the arrival platoon as a function of time for each cycle. Average running speed indicates that the time offset between the two trailers is approximately $35 \mathrm{~s}$. The start and end of the platoon's arrival can be estimated with Equations 8 and 9.

$$
\begin{gathered}
t_{a, i, n, \mathrm{start}}=t_{\mathrm{on}, i, n}+D_{i} / V_{i} \\
t_{a, i, n, \text { end }}=t_{\mathrm{off}, i, n}+D_{i} / V_{i}
\end{gathered}
$$

where

$t_{a, i, n, \text { start }}=$ start time of the arrival platoon for cycle $n$ at site $i$,

$t_{a, i, n, \text { end }}=$ end time of the arrival platoon for cycle $n$ at site $i$,

$D_{i}=$ distance from upstream trailer to the downstream trailer at site $i$, and

$V_{i}=$ average platoon running speed at site $i$.

The time window, defined as the difference between $t_{a, i, n, \text { start }}$ and $t_{a, i, n, \text { nd }}$, may be too wide and, if so, might include vehicles (e.g., turning vehicles) not considered part of the platoon. Thus, the critical headway is used to identify those vehicles that should be part of the platoon and exclude those that should not. A sensitivity analysis of the critical headway ranging from 2 to $10 \mathrm{~s}$ was conducted. The objective was to optimally match the identified arrival platoons to the discharge platoons with respect to the number of platoons and their respective sizes. A 5-s headway gave the best results with respect to matching the total number of platoons and the size of each platoon at the upstream and downstream trailers.

\section{Verification of Travel Time in SSD Data}

Two methods were used to extract data for identifying the platoon and the platoon travel time. First, 25 continuous signal cycles were extracted from the SSD data, and these 25 platoons were identified with the platoon identification process introduced in the previous section. The individual travel time was recorded from SSD 2 (upstream) to SSD 1 


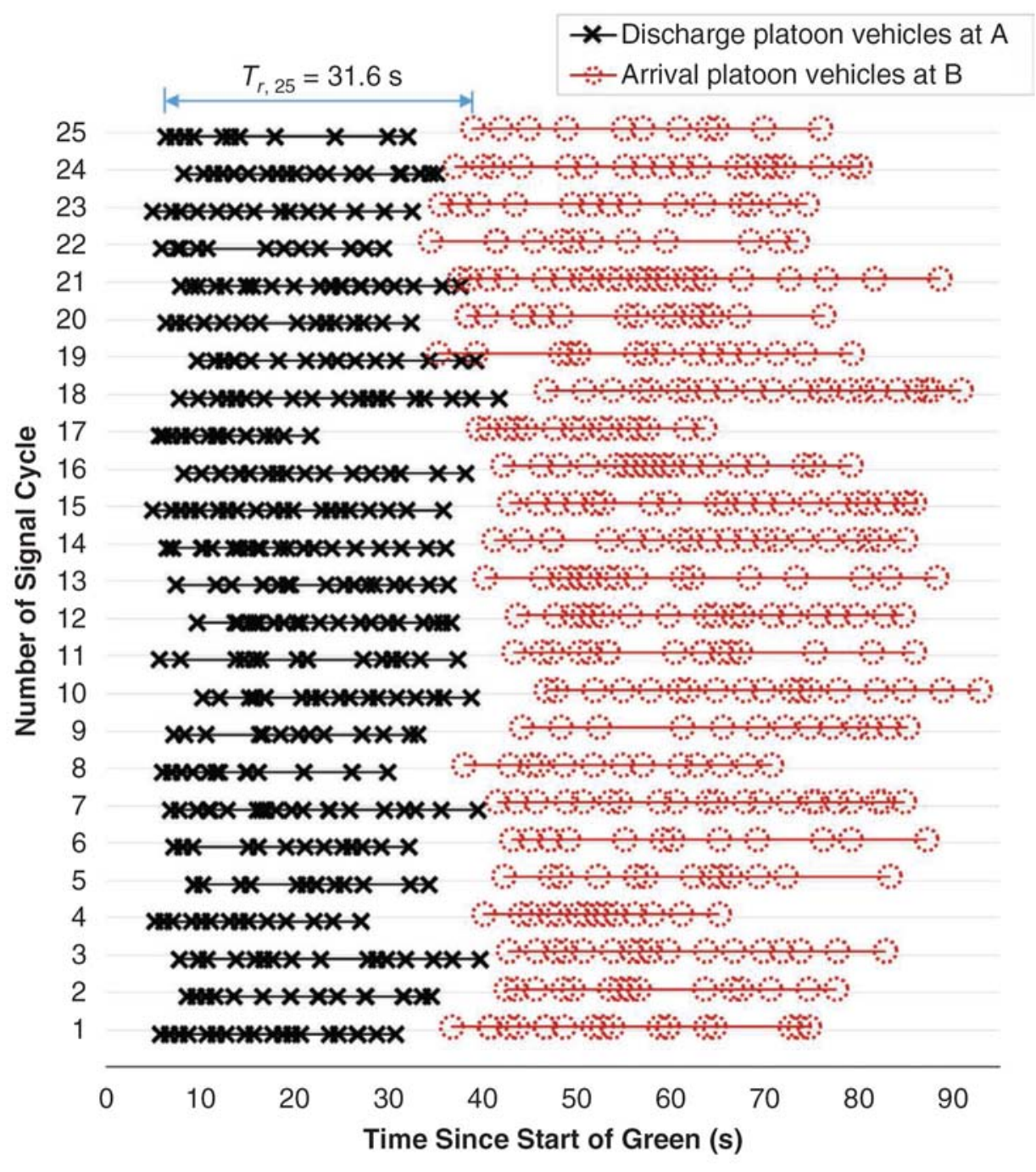

Figure 4. Examples of discharge and arrival platoon vehicles at Site 3, June 4, 2016.

(downstream) for all vehicles in each platoon that was discharged from the upstream green phase.

Figure 4 shows the 25 platoons collected by SSD at Site 3 on June 4, 2016. $\mathrm{T}_{r, 25}$ indicates the running time between the first recorded discharge vehicle and first recorded arrival vehicle in the 25th platoon. In the same manner, the running times for the other vehicles in the 25th platoon can be obtained. The average of the running times of all vehicles in the platoon yield the average travel time for this particular platoon. The average of all the platoons' travel time yields the average platoon travel time $\left(t_{0}\right)$, which will be used for calibration of the PD parameters at this site. 
Figure 4 shows that the time headway of the vehicles in the platoon at the upstream location is much tighter compared with the headway of the vehicles in the downstream platoon. The differences in the time length of the platoon (i.e., the time of the last vehicle in the platoon minus the time of the first vehicle in the platoon) at the upstream trailer and the downstream trailer was averaged for the 25 platoons. The average travel time of the 25 platoons was $12.8 \mathrm{~s}$, and the standard deviation was $4.2 \mathrm{~s}$.

According to information obtained from the video, 25 platoons from the same 25 cycles were also obtained. The platoons that were identified manually from the video and those identified from the automatic process were compared. The PD parameter estimation method of Yu and Van Aerde requires only the platoon travel time $t_{o}$ and the variance $\sigma^{2}$ to (17). These variables collected from the 25 platoons at each test site by the SSD and video methods are listed in Table 3.

As shown in Table 3, the mean of the travel time obtained from the SSD data was $8 \%$ and 3\% higher, compared with the video observation for Sites 1 and 3, respectively. A t-test found there was no statistically significant difference in the mean travel time between the two methods at the $95 \%$ level of confidence. It was concluded that the travel time estimation with the SSD method was appropriate. However, the recorded video at Site 2 was lost because of a camera malfunction. Later, an effort was made to manually observe the running time between the two trailers at Site 2 . The mean of the travel time for Site 2 was $34.27 \mathrm{~s}$, with a variance of $4.79 \mathrm{~s}$, providing a reference for validity of the SSD data from Site 2.

Table 3. Data reduction statistics for test sites

\begin{tabular}{cccccccc} 
Site & Method & $\begin{array}{c}\text { Number of } \\
\text { Platoons }\end{array}$ & $\begin{array}{c}\text { Mean of } \\
\text { Travel Time (s) }\end{array}$ & $\begin{array}{c}\text { SD of Travel } \\
\text { Time (s) }\end{array}$ & $\begin{array}{c}\text { Diff. of Mean } \\
\text { Travel Time }\end{array}$ & t-Stat. & $p_{\text {-Value }}{ }^{b}$ \\
\hline 1 & SSD & 25 & 32.71 & 2.34 & 2.53 & 1.27 & .209 \\
& Video & 25 & 30.18 & 1.75 & 2.53 & 1.27 & .209 \\
2 & SSD & 25 & 35.43 & 2.20 & - & - & - \\
& Video & - & - & - & - & - & - \\
3 & SSD & 25 & 37.62 & 3.77 & 1.38 & 1.26 & .216 \\
& Video & 25 & 36.24 & 3.97 & 1.38 & 1.26 & .216 \\
\hline
\end{tabular}

- = data missing.

a. Difference of mean travel time measured by SSD method and video method for each site.

b. Significance level $=0.05$. 


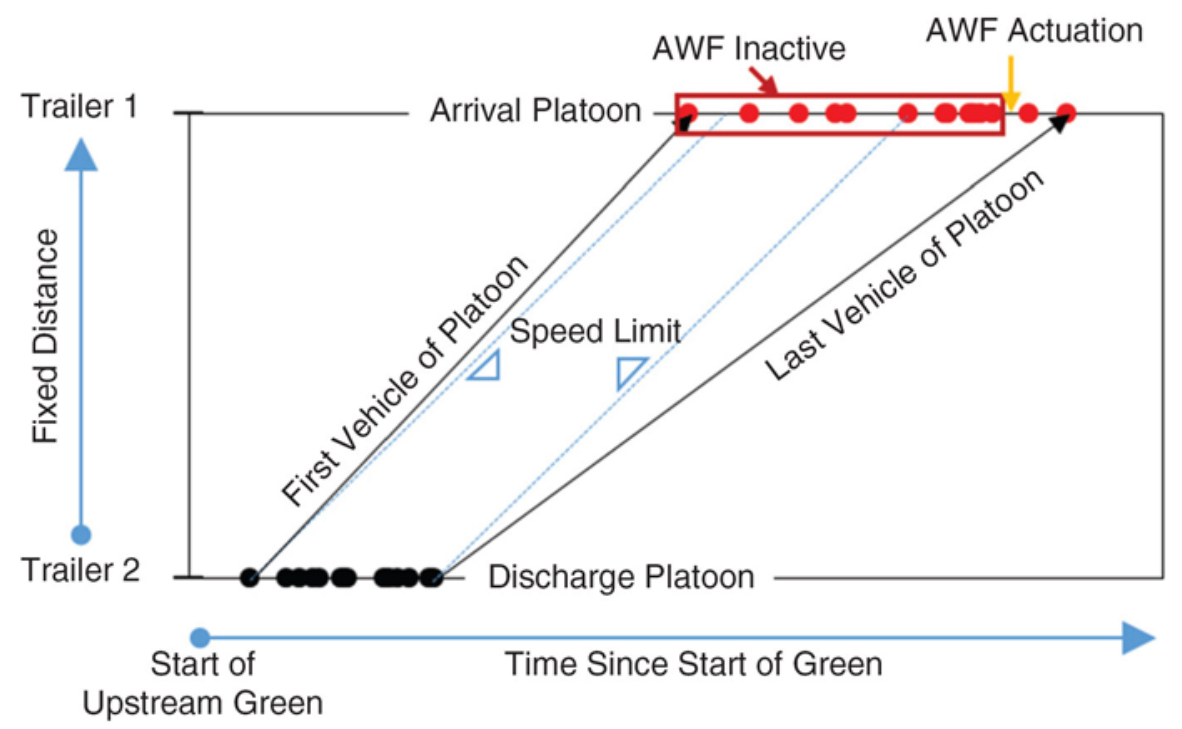

Figure 5. Example of platoon vehicles encountering actuated AWF at Site 3.

\section{Effect of AWF on Calibration of Arrival Flow Profiles}

If all vehicles in a platoon travel at the same speed (e.g., the speed limit), there will be no dispersion, as illustrated by the dashed lines in Figure 5. However, in reality, the platoon will disperse so that the first portion of the arrival platoon vehicles will pass by the AWF before the AWF is active. Vehicles in this part of the platoon (e.g., not affected by the AWF) are indicated by the rectangle in Figure 5. When the AWF is actuated, it is assumed that the vehicles upstream of the AWF will recognize and react to the flashing signal.

Different green time durations have different AWF start times. To compare the platoons, the green time durations must all be equal. Therefore, only green time intervals of $30 \mathrm{~s}$ were selected from the data at each site because this was the most frequently observed green time. The average number of vehicles in each platoon was 14.6 to 17.4 , with standard deviation of 4.9 to 7.6 vehicles at the three test sites. Robertson's PD model was calibrated to the two regimes: AWF inactive and AWF active. The AWF inactive regime refers to the situation in which the AWF is inactive during the downstream green time when the platoon passes by. The AWF active regime refers to the situation in which the AWF is activated and drivers in the tail end of the platoon see the warning flashers. If the AWF does not affect PD, it is hypothesized that there will be 
Table 4. Comparison of PD parameters with and without AWF effect

\begin{tabular}{ccccc} 
Site & $\begin{array}{c}\text { Platoon Vehicle } \\
\text { Regime }\end{array}$ & $\begin{array}{c}\text { Calibrated } P D \\
\text { Coefficient, } \alpha\end{array}$ & $\begin{array}{c}\text { Calibrated } \\
\text { Platoon } \\
\text { Arrival Time } \\
\text { Coefficient, } \beta\end{array}$ & $\begin{array}{c}\text { Calibrated } \\
\text { Smoothing } \\
\text { Factor, } F\end{array}$ \\
\hline 1 & AWF inactive & 0.085 & 0.921 & 0.28 \\
2 & AWF active & 0.224 & 0.817 & 0.13 \\
3 & AWF inactive & 0.118 & 0.895 & 0.21 \\
& AWF active & 0.222 & 0.819 & 0.13 \\
& AWF inactive & 0.137 & 0.879 & 0.19 \\
& AWF active & 0.287 & 0.777 & 0.11 \\
\hline
\end{tabular}

no difference in the calibration parameters between the two regimes. Equations 3, 4, and 5 were used to estimate the PD parameters for each site and for each regime. The results are listed in Table 4.

As shown in Table 4, the dispersion coefficient, $\alpha$, for the three sites ranges from 0.085 to 0.137 when the AWF is inactive and from 0.222 to 0.287 when the AWF is active. Both ranges are lower than the default value of 0.35 recommended by Robertson (3). The higher value of $\alpha$ associated with the AWF effect indicates an increase in roadway friction (i.e., longer platoon travel time). The platoon arrival time coefficient, $\beta$, ranges from 0.777 to 0.819 when the AWF is active. This is approximately the same as the default value of 0.8 recommended by Robertson (3). The smoothing factor, $F$, ranges from 0.11 to 0.13 when the AWF effect is included in the parameter estimation. This is smaller than the smoothing factor for platoons without considering the AWF effect.

Next, the arrival flow profiles were predicted in Robertson's model with the estimated coefficients. Figure 6 shows the observed flow rates at the upstream and downstream trailers and the predicted flow rate at the downstream trailer for Sites 1, 2, and 3, respectively. For the three sites, the solid-point curves represent the discharge flow profile observed at the upstream trailer, and the sold curves represent the arrival flow profile observed at the downstream trailer. The arrival flow profile describes the platooned arrivals from the upstream intersection during the green phase, which may consist of two sources: through vehicles and right-turn vehicles during the upstream green phase. The arrival flow rates, at 1-s time steps from the start of green in each cycle, were averaged for all signal cycles during the data analysis period.

Given the observed discharge flow and arrival flow profiles, the predicted arrival flow profile can be estimated by using the two sets of coefficients from Table 4. As compared in Figure 6, the dotted curves are the 


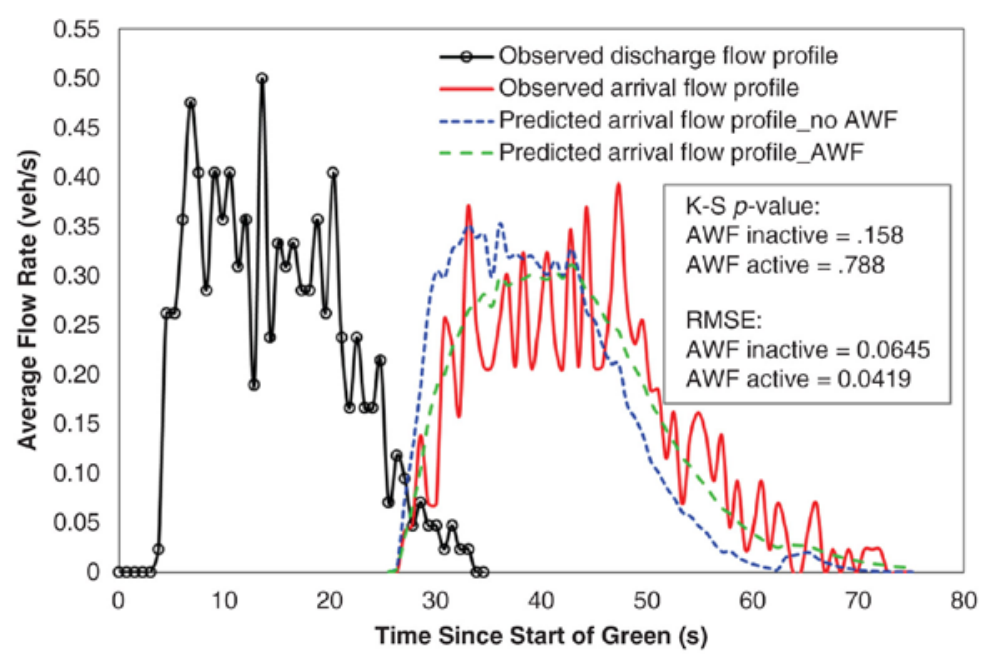

(a)

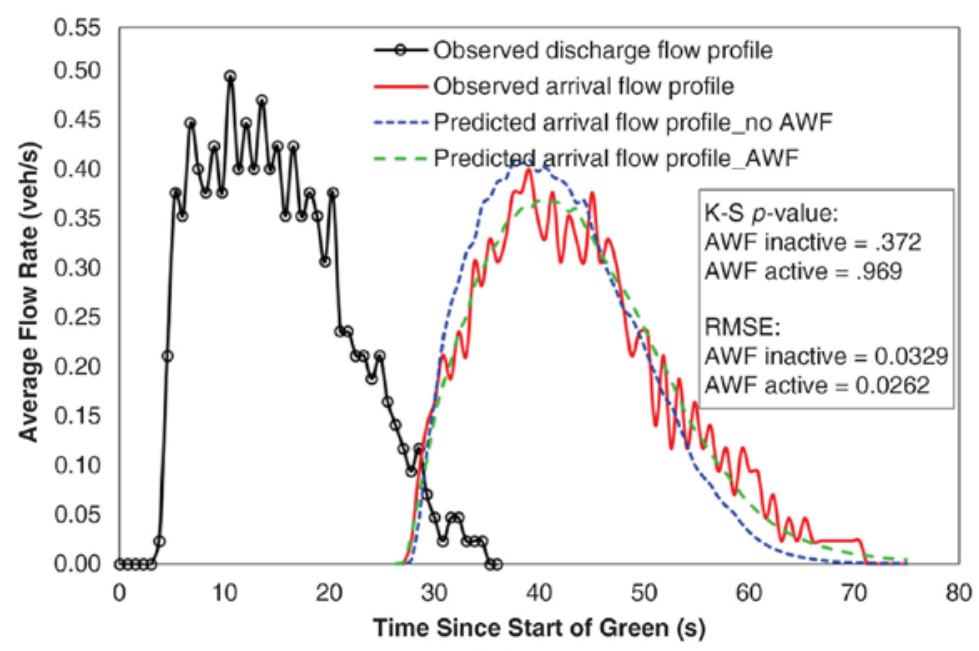

(b)

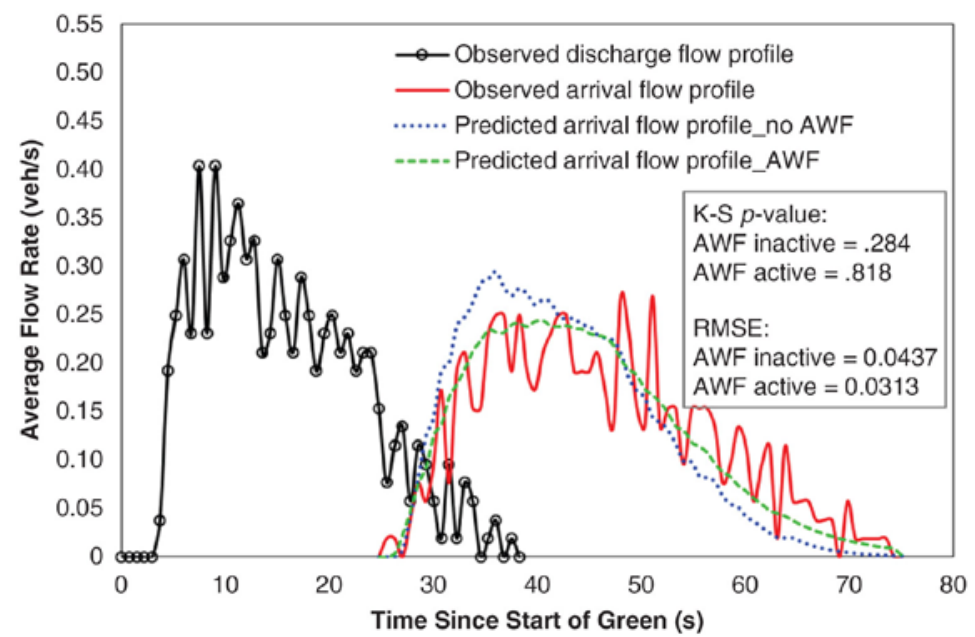

(c)

Figure 6. Fitted arrival flow profiles for both AWF inactive and AWF active regimes, upstream and downstream: (a) Site 1, (b) Site 2, and (c) Site 3 (K-S = KolmogorovSmirnov; RMSE = root mean square error). 
fitted arrival profiles assuming an AWF inactive regime, and the dashed curves are the fitted arrival flow profiles assuming an AWF active regime and that some vehicles in the platoon will see the AWF and react to it. Under the AWF active regime, the total platoon constitutes vehicles that are both unaffected by the AWF (e.g., front portion of a platoon) and affected by the AWF (e.g., tail portion of the platoon). The average number of vehicles in a platoon affected by the AWF was 3.44, with a standard deviation of 1.8 vehicles for the calibration platoons $(N=75)$.

In general, the arrival flow dispersion is underestimated when the effect of the AWF is not included in the calibrated model. As shown for the AWF inactive regime (i.e., dotted curves) in Figure 6, the right-hand tails of the predicted arrival flow profiles shrink earlier than the observed arrival flow profiles after actuation of the AWF. This is particularly true when the observed discharge flow rates fluctuate greatly (e.g., Sites 1 and 3). From a visual check of fit of the model, the observed arrival flow profiles are better fitted by the AWF active regime (i.e., dashed curves) in Figure 6. In other words, the effect of AWF is to elongate or delay the arrival platoon. This conclusion supports the finding that the calibrated $\alpha$ value was higher for the AWF active regime compared with the AWF inactive regime in Table 4.

In addition, the $p$-value from the two-sample Kolmogorov-Smirnov test is used to statistically indicate the model's goodness of fit. The null hypothesis is that the observed arrival flow and the predicted arrival flow (e.g., in the two regimes) have the same distribution. A small $p$ value indicates any violation of that null hypothesis, such as different medians, different variances, or different distributions. As the $p$-values shown in Figure 6 indicate, the arrival profiles incorporating the AWF effect are better fitted compared with those that do not incorporate the AWF effect. Also shown in Figure 6 is the RMSE that measures the predicted arrival flow profiles with the observed arrival flow profiles for both regimes. The smaller RMSE associated with the AWF active regime indicates that it reduces the error, compared with the AWF inactive regime, by $20 \%$ to $35 \%$.

\section{Concluding Remarks}

Robertson's PD model, as the core of the TRANSYT simulation model, is probably the most widely used PD model in the world. Traffic flow 
dispersion models are very important to properly estimating traffic flow and are key to optimizing traffic signal timing plans or safety strategies on signalized corridors. This paper studied the traffic flow dispersion patterns on a coordinated signalized corridor equipped with AWF by using the calibrated Robertson's PD model. The purpose was to calibrate the dispersion parameters while considering the effect of the AWF and to test the hypothesis that the AWF affects the dispersion parameters. To achieve this goal, platoon vehicles that were not involved with AWF were used for comparison.

When the AWF effect is considered in the parameter estimation, the smoothing factor $F$ ranges from 0.11 to 0.13 , which is smaller than the smoothing factor estimated without the AWF effect (which ranges from 0.19 to 0.28 ). The PD coefficient $\alpha$ increases from an average of 0.11 with the AWF effect to an average of 0.24 without the AWF effect, indicating an increase of friction in the road traffic. As the only change is the existence of the AWF, it was concluded that the AWF affects (i.e., increases) PD.

PD models other than Robertson's model should be explored with respect to the AWF scenario. Also, the TRANSYT simulation model could be used to verify the effectiveness of the calibrated coefficients for improving the corridor signal coordination. It is recommended that the calibration of Robertson's PD model consider the AWF effect when the signal coordination dispersion parameters are applied, either in practice or in simulation, as the AWF will affect the vehicles at the tail end of the arrival platoon.

Acknowledgments - The authors thank the research sponsor, the Nebraska Department of Roads, for its support. In addition, the authors thank the City of Grand Island, Nebraska, for help collecting the data.

\section{References}

1. Sunkari, S. R., C. J. Messer, and H. A. Charara. Performance of Advance Warning for End of Green System for High-Speed Signalized Intersections. Transportation Research Record: Journal of the Transportation Research Board, No. 1925, 2005, pp. 176-184. https://doi.org/10.3141/1925-18

2. Appiah, J. L., R. Rilett, B. Naik, and R. Wojtal. Driver Response to an Actuated Advance Warning System. Journal of Transportation Engineering, Vol. 139, No. 5, 2013, pp. 433-440. https://doi.org/10.1061/(ASCE)TE.1943-5436.0000522 
3. Robertson, D. I. TRANSYT: A Traffic Network Study Tool. Report RL-253. Road Research Laboratory, Wokingham, England, 1969.

4. Wallace, C. E., K. G. Courage, and D. P. Reaves. TRANSYT-7F User's Manual. University of Florida, Gainesville, 2003.

5. Yu, L. Calibration of Platoon Dispersion Parameters on the Basis of Link Travel Time Statistics. Transportation Research Record: Journal of the Transportation Research Board, No. 1727, 2000, pp. 89-94. https://doi.org/10.3141/1727-11

6. Courage, K., C. E. Wallace, and M. A. Hadi. TRANSYT-7F Users Guide. FHWA, U.S. Department of Transportation, 1991.

7. Tarnoff, P. J., and P. S. Parsonson. NCHRP Report 233: Selecting Traffic Signal Control at Individual Intersections, TRB, National Research Council, Washington, D.C., 1981.

8. McCoy, P. T., E. A. Balderson, R. T. Hsueh, and A. K. Mohaddes. Calibration of TRANSYT Platoon Dispersion Model for Passenger Cars Under Low-Friction Traffic Flow Conditions (Abridgment). Transportation Research Record, No. 905, 1983, pp. 48-52.

9. Seddon, P. A. Another Look at Platoon Dispersion: 3. The Recurrence Relationship. Traffic Engineering and Control, Vol. 13, No. 10, 1972, pp. 442-444.

10. Bonneson, J. A., M. P. Pratt, and M. A. Vandehey. Predicting Arrival Flow Profiles and Platoon Dispersion for Urban Street Segments. Transportation Research Record: Journal of the Transportation Research Board, No. 2173, 2010, pp. 28-35. https://doi.org/10.3141/2173-04

11. Collins, J. F., and P. Gower. Dispersion of Traffic Platoons on A4 in Hounslow. Report SR 29UC. Transport and Road Research Laboratory, Wokingham, England, 1974.

12. El-Reedy, T. Y., and R. Ashworth. Platoon Dispersion Along a Major Road in Sheffield. Traffic Engineering and Control, Vol. 19, 1978, pp. 186-189.

13. Axhausen, K. W., and H.-G. Körling. Some Measurements of Robertson's Platoon Dispersion Factor. Transportation Research Record, No. 1112, 1987, pp. 71-77.

14. Day, C. M., and D. M. Bullock. Calibration of Platoon Dispersion Model with HighResolution Signal Event Data. Traffic Signal Systems, Vol. 2311, 2012, pp. 16-28.

15. Yu, L. Real-Time Calibration of Platoon Dispersion Model to Optimize the Coordinated Traffic Signal Timing in ATMS Networks. Center for Transportation Training and Research, Texas Southern University, Houston, 1999.

16. Guebert, A. A., and G. Sparks. Timing Plan Sensitivity to Changes in Platoon Dispersion Settings. In Proceedings of the Fifth NG Foundation Conference on Traffic Control Methods, Santa Barbara, Calif., 1990.

17. Yu, L., and M. Van Aerde. Implementing TRANSYT's Macroscopic Platoon Dispersion in Microscopic Traffic Simulation Models. Presented at 74th Annual Meeting of the Transportation Research Board, Washington, D.C., 1995.

18. Yu, L. Platoon Dispersion and Calibration Under Advanced Traffic Control Strategies. In Traffic Congestion and Traffic Safety in the 21st Century: Challenges, Innovations, and Opportunities (R. F. Benekohal, ed.), Conference proceedings, ASCE, New York, 1997, pp. 507-513. 